Article

\title{
Is There a Significant Difference in Accuracy of Four Intraoral Scanners for Short-Span Fixed Dental Prosthesis? A Comparative In Vitro Study
}

\author{
Anca Jivănescu 1,+(i), Adrian Bara ${ }^{2,+}$, Andrei-Bogdan Faur ${ }^{2, *,+}$ (i) and Raul Nicolae Rotar ${ }^{1,+}$ (i) \\ 1 TADERP Research Center, Department of Prosthodontics, University of Medicine and Pharmacy \\ "Victor Babes", B-dul Revolutiei 1989, No. 9, 300580 Timisoara, Romania; ajivanescu@yahoo.com (A.J.); \\ rotarraul3@yahoo.com (R.N.R.) \\ 2 Department of Prosthodontics, University of Medicine and Pharmacy “Victor Babes", B-dul Revolutiei 1989, \\ No. 9, 300580 Timisoara, Romania; adibara2004@yahoo.com \\ * Correspondence: faur_andy@yahoo.com; Tel.: +40-744673091 \\ + These authors contributed equally to this work.
}

check for

updates

Citation: Jivănescu, A.; Bara, A.; Faur, A.-B.; Rotar, R.N. Is There a Significant Difference in Accuracy of Four Intraoral Scanners for Short-Span Fixed Dental Prosthesis? A Comparative In Vitro Study. Appl. Sci. 2021, 11, 8280. https://doi.org/ 10.3390/app11188280

Academic Editors: Bruno Chrcanovic and Antonio Scarano

Received: 19 July 2021

Accepted: 1 September 2021

Published: 7 September 2021

Publisher's Note: MDPI stays neutral with regard to jurisdictional claims in published maps and institutional affiliations.

Copyright: (c) 2021 by the authors. Licensee MDPI, Basel, Switzerland. This article is an open access article distributed under the terms and conditions of the Creative Commons Attribution (CC BY) license (https:/ / creativecommons.org/licenses/by/ $4.0 /)$.

\begin{abstract}
Is the accuracy of the older generation of IOSs an impediment for obtaining a quality intraoral digital impression? The aim of this study was to evaluate the differences in accuracy between four intraoral scanners (two of the latest IOSs and two older IOSs) in the scenario of a short span fixed partial denture, and to determine if these differences have a major impact on the quality of the final digital impression. Four intraoral scanners: Cerec PrimeScan, Medit i700, Cerec Omnicam and Planmeca PlanScan and one laboratory scanner were used in this study. The scanned data were processed with the help of Geomagic Control X, a metrology software. For the statistical data analysis, the level of significance was set as $0.05(\alpha=0.05)$. The Medit 1700 group displayed the best level of trueness with the median value of $23.25 \mu \mathrm{m}$, PrimeScan group with a median of $25.55 \mu \mathrm{m}$, Omnicam group with a median of $32.3 \mu \mathrm{m}$ and the PlanScan group which displayed the lowest level of trueness with a median value of $75.8 \mu \mathrm{m}$. From the precision data analysis, it was concluded that the PrimeScan group showed the best results, followed by Medit i700, Omnicam and the PlanScan group which showed the lowest precision. Even if there are some significant differences in accuracy between old and new IOSs, in the in vitro scenario of short span dental prostheses, the accuracy values were within the clinically acceptable range and may present important clinical implications.
\end{abstract}

Keywords: intraoral scanner; trueness; precision; accuracy; fixed dental prostheses

\section{Introduction}

Today, acquiring an intraoral scanner (IOS) for the dental office can be a major step forward for both the quality of the treatments and the overall impression for the patient also serving as an ideal marketing tool [1]. However, the latest IOSs can be a big investment for the dental office and not all dentists may be able to afford it. Thus, the following question arises: are the IOSs released in the previous years a good and reliable alternative to the latest scanners emerging on the market?

The clinical applications of intraoral scanners (IOSs) have increased significantly providing dentists with relevant information that enhance the entire treatment plan and procedure. Minimally invasive dentistry with inlays, onlays and veneers, as well as short span prosthetic restorations, full arch rehabilitation and implant supported restorations can be successfully obtained with the aid of these systems [2-5].

One of the main advantages of IOSs is the possibility to completely replace the conventional impression, reducing the discomfort for the patient, the working procedure and the overall costs of the impression materials. The immediate evaluation of the quality of the digital impression is another beneficial aspect that enhances the impression procedure [6-9]. These systems also have a number of limitations including the difficulty in detection of 
deep preparation margins, the presence of blood and saliva prevents data acquisition of the scanned surface, and also high purchasing and maintenance costs [10].

A key aspect for any long lasting prosthetic restoration is the accuracy of the impression which generates a working model (digital or conventional) that eventually dictates the marginal adaptation and fit of the final restoration. Two variables, "trueness" and "precision", describe the accuracy of a measurement method (ISO 5725). "Trueness" refers to the closeness of agreement between the arithmetic mean of a large number of test results and the true or accepted reference value. "Precision" refers to the closeness of agreement between test results [11-13].

The analysis of the trueness involves a reference virtual model that is generally obtained with an industrial or a desktop laboratory scanner (with accuracy $<5 \mu \mathrm{m}$ ). This high-quality virtual model is then overlapped in a 3D inspection software with the virtual model obtained with the intraoral scanner which shows the differences and similitudes between the meshes [14-16].

Primescan (CEREC v.5, Dentsply-Sirona Dental Systems, Bensheim, Germany, 2019) is the latest intraoral scanner from CEREC and uses high-resolution sensors and shortwave light with optical high-frequency contrast analysis for dynamic deep scan $(20 \mathrm{~mm})$ [17].

i700 (Medit Link v2.4.4, Medit, Seoul, Korea, 2021) is the latest intraoral scanner from Medit, improving most of the features presented by Medit i500. Data acquisition is based on the principle of 3D in Motion Video Technology/3D Full Color Streaming Capture [18].

CEREC Omnicam (v4.6 Dentsply-Sirona Dental Systems, Bensheim, Germany, 2012), the predecessor of Primescan, is based on the principle of confocal microscopy and active triangulation with a white LED light source [17].

The Planmeca PlanScan (Romexis v4.6.2, powered by E4D Technologies, LLC, Richardson, TX, USA, 2014) works based on the principle of optical coherence tomography and confocal microscopy. It is incorporated with a blue light real-time laser video streaming technology [17].

Medit T500 (Seoul, Korea) is a desktop dental scanner with an accuracy of $<7 \mu \mathrm{m}$, that works based on the principle of phase-shifting optical triangulation, using a blue LED light source [19].

Additional information about the intraoral scanners is provided in Table 1.

Table 1. Table displaying additional information about the selected IOSs.

\begin{tabular}{|c|c|c|c|}
\hline IOS & Manufacturer & Software & Features \\
\hline $\begin{array}{l}\text { CEREC Primes- } \\
\text { can (2019) }\end{array}$ & $\begin{array}{l}\text { Dentsply-Sirona } \\
\text { Dental Systems, } \\
\text { Bensheim, Ger- } \\
\text { many }\end{array}$ & $\begin{array}{l}\text { Sirona Connect } \\
5.1(2019)\end{array}$ & $\begin{array}{l}\text { High-resolution sensors } \\
\text { and shortwave light with } \\
\text { optical high-frequency } \\
\text { contrast analysis for } \\
\text { dynamic deep scan } \\
(20 \mathrm{~mm})\end{array}$ \\
\hline $\begin{array}{l}\text { Medit } \\
(2021)\end{array}$ & $\begin{array}{l}\text { Medit, Seoul, South } \\
\text { Korea }\end{array}$ & $\begin{array}{l}\text { Medit Link 2.4.4 } \\
(2021)\end{array}$ & $\begin{array}{l}\text { 3D in Motion Video } \\
\text { Technology/3D Full Color } \\
\text { Streaming Capture }\end{array}$ \\
\hline $\begin{array}{l}\text { CEREC Omni- } \\
\text { cam (2012) }\end{array}$ & $\begin{array}{l}\text { Dentsply-Sirona } \\
\text { Dental Systems, } \\
\text { Bensheim, Ger- } \\
\text { many }\end{array}$ & $\begin{array}{l}\text { Sirona Connect } \\
4.6 .0(2018)\end{array}$ & $\begin{array}{l}\text { Confocal microscopy and } \\
\text { active triangulation with a } \\
\text { white LED light source }\end{array}$ \\
\hline $\begin{array}{l}\text { Planmeca Plan- } \\
\text { scan (2014) }\end{array}$ & $\begin{array}{l}\text { E4D Technologies, } \\
\text { LLC, Richardson, } \\
\text { TX, USA }\end{array}$ & $\begin{array}{l}\text { Planmeca } \\
\text { Romexis } 4.6 .2 \\
\text { (2018) }\end{array}$ & $\begin{array}{l}\text { Optical coherence tomog- } \\
\text { raphy and confocal mi- } \\
\text { croscopy }\end{array}$ \\
\hline
\end{tabular}

The aim of this study was to evaluate the differences in accuracy between four intraoral scanners in the scenario of a short span fixed partial denture and to determine 
if the improved accuracy could have a major impact on the final outcome of the digital impression procedure.

The null hypothesis was that the latest IOSs will generate significantly higher accuracy values when compared with IOSs released more than five years ago (to the date of the present study).

\section{Materials and Methods}

Four intraoral scanners: Cerec PrimeScan, Medit i700, Cerec Omnicam and Planmeca PlanScan and one laboratory scanner (Medit T500) were used in this study.

We considered IOSs released more than five years ago as being part of the old generation of IOSs. The two old generation scanners selected for this study were Planmeca PlanScan and Cerec Omnicam. The new generation includes recently launched IOSs that are considered by the manufacturer to be the most advanced and developed in technology and software, also being their current flagship product. Medit i700 and Cerec Primescan were selected as the new generation scanners to be tested in this study.

A typodont (AG-3; Frasaco, Tettnang, Germany) was selected for the study. Full all ceramic crown preparations with deep chamfer, $1 \mathrm{~mm}$ of axial reduction and $1.5 \mathrm{~mm}$ of occlusal reduction were manually conducted on the left mandibular second premolar and on the left mandibular second molar of the typodont. An edentulous area was present in place of the left mandibular first molar, obtained after removing the tooth from the typodont and filling the gap with polyvinyl siloxane (Elite HD+, Zhermack, Badia Polesine, Italy).

Ten consecutive scans were performed by a single operator with each intraoral scanner in order to obtain the 3D meshes to be compared with the reference data. The scanning path was identical for all the IOS's starting on the occlusal surface of the distal abutment, coming to the buccal of both abutments and the edentulous area, then, the occlusal surface of mesial abutment and edentulous area and finishing with the lingual surfaces. Calibration was performed according to the manufacturer's instructions. All the scans were performed in the same day, around the same time, the light intensity being verified to be constant during all of the scans with the help of a lux-meter (GM1010, Benetech, Shenzhen, China). During the scanning procedure, the typodont was mounted inside the phantom (Phantom head PK-2 TSE; Frasaco) and the position of the assembly was not moved or altered in any way between the scans. Consequently, 40 STL files were obtained: 10 meshes for PrimeScan, 10 meshes for i700, 10 meshes for Omnicam and 10 meshes for PlanScan.

The desktop dental scanner Medit T500 was used to obtain the reference scan in standard tessellation language (STL). The calibration of the desktop scanner was performed according to the manufacturer's instructions in order to obtain a highly accurate 3D model (the reference model). The scanned data were processed with the help of Geomagic Control X (Version:16.0.2.16496, 3D Systems, Wilsonville, OR, USA), a complete metrology grade, quality control software used for analyzing and comparing 3D meshes. The reference data were uploaded into the software and the area of interest including the two prepared teeth and the edentulous area was isolated from the rest of the mesh. The isolating procedure was done manually inside the software, respecting the margins of the preparations and the boundary of the polyvinyl siloxane that simulated the edentulous area. For consistency, the area of interest remained the same for all the following comparisons, not being necessary to retrace the margins of the area of interest as the reference data remain the same and only the measured data are being swapped. The intraoral scanner mesh was uploaded into the software as measured data to be compared with the reference data. Only the isolated area of interest was analyzed between the meshes, in order to focus on the scanning accuracy of the area for the fixed partial denture, excluding the remaining area of the typodont.

The "initial alignment" function was executed to superimpose the intraoral scanner mesh over the reference mesh followed by the "best fit alignment" that concentrates on the alignment of the isolated area of interest in order to secure a precise overlapping of the two meshes. In order to analyze the deviation between the reference and measured data, the "3D Compare" function was used by projecting all paired points onto the reference data. 
A color-coded map was rendered displaying the deviation patterns of the investigated surfaces. The color-coded map was set to display deviations between $\pm 50 \mu \mathrm{m}$. On the color-coded map scale, outward displacement is presented towards the red spectrum while inward displacement is presented towards the blue spectrum. The areas with no deviation between the analyzed mesh and the reference one, are being presented in green as there is less than $\pm 1 \mu \mathrm{m}$ between the compared surfaces in that specific area (Figure 1).

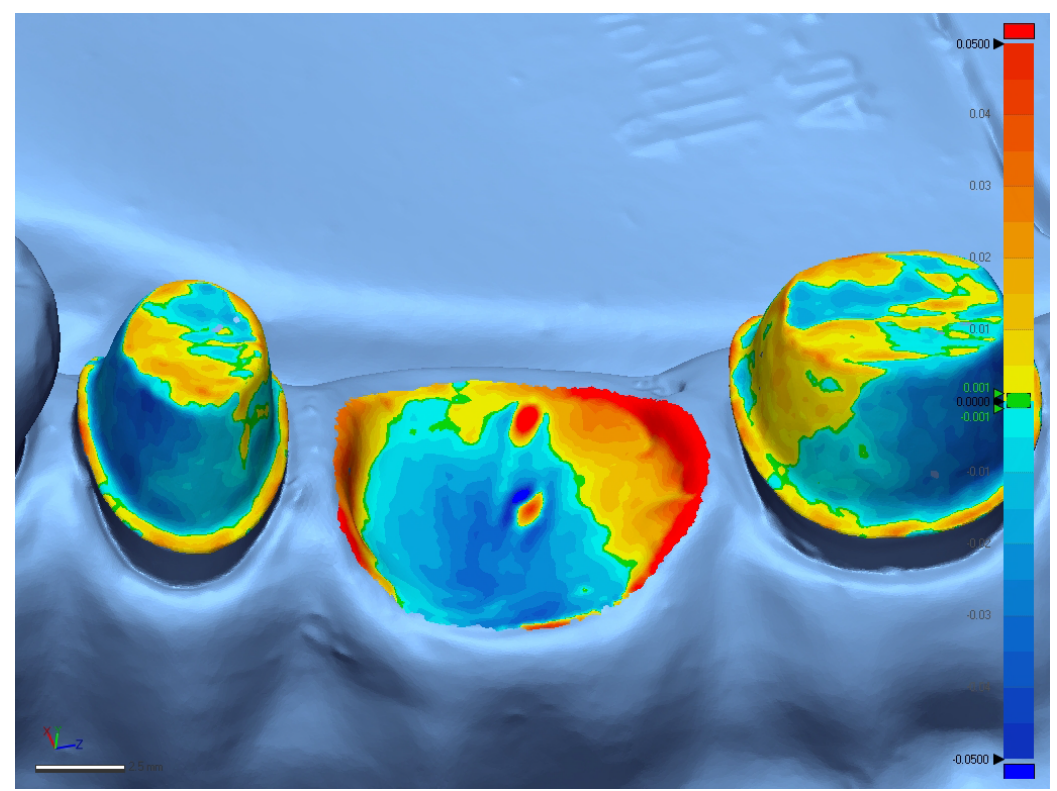

Figure 1. Color-coded map of the analyzed area. Deviation is displayed in $\mathrm{mm}$ on the color scale with outward (red) and inward (blue) displacement.

The entire process was executed for all the intraoral scanner meshes in order to obtain the numerical values for trueness (Figure 2). To obtain the precision values, each intraoral scanner mesh was compared with all the other meshes within its group following the same protocol.

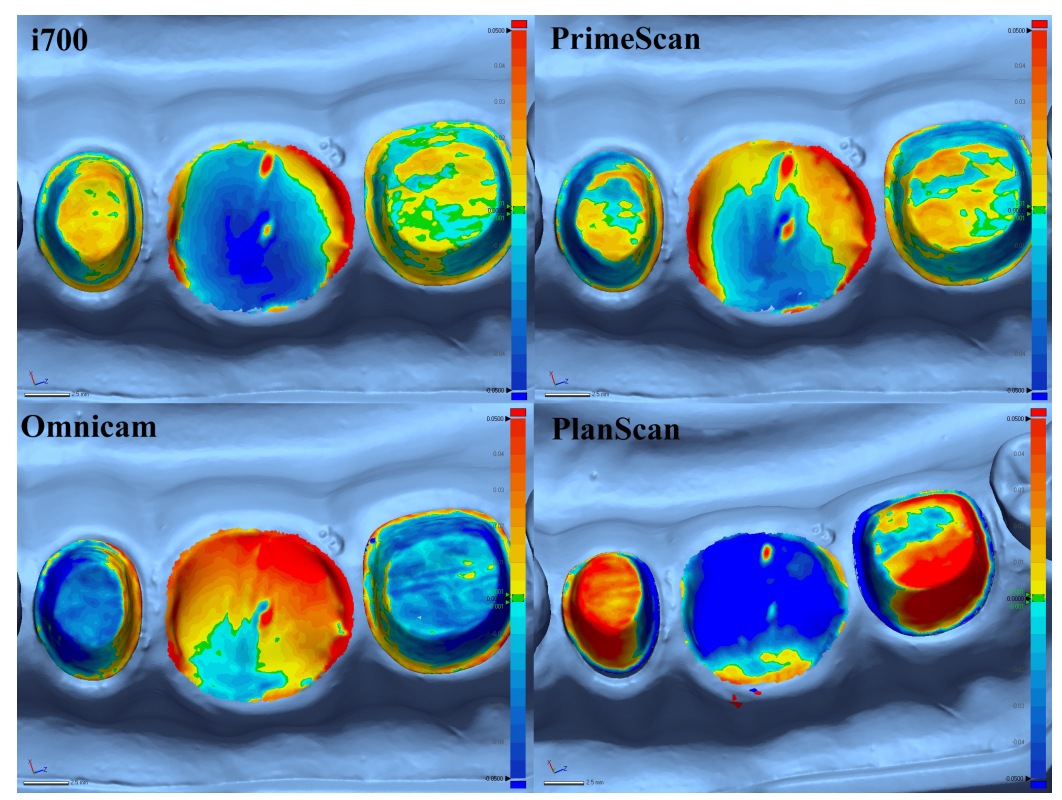

Figure 2. Trueness color-coded maps generated by the metrology software.

The statistical analysis was conducted by uploading the standard deviation data obtained from the metrology software into the MedCalc statistical software. The Kolmogorov- 
Smirnov test resulted that both the data for trueness and precision were non-parametric. To further analyze the data, the Kruskal-Wallis test was used on the datasets. The level of significance was set to $\alpha=0.05$.

\section{Results}

Table 2 presents the trueness values while Table 3 presents the precision values.

Table 2. Data obtained when comparing for trueness.

\begin{tabular}{ccccc}
\hline & Primescan & i700 & Omnicam & PlanScan \\
\hline M1 & $21.7 \mu \mathrm{m}$ & $25.6 \mu \mathrm{m}$ & $40.4 \mu \mathrm{m}$ & $76 \mu \mathrm{m}$ \\
M2 & $23.4 \mu \mathrm{m}$ & $25.5 \mu \mathrm{m}$ & $31.7 \mu \mathrm{m}$ & $68.5 \mu \mathrm{m}$ \\
M3 & $33.3 \mu \mathrm{m}$ & $26.9 \mu \mathrm{m}$ & $32.2 \mu \mathrm{m}$ & $66.6 \mu \mathrm{m}$ \\
M4 & $26.1 \mu \mathrm{m}$ & $23.9 \mu \mathrm{m}$ & $43.4 \mu \mathrm{m}$ & $96.1 \mu \mathrm{m}$ \\
M5 & $21.3 \mu \mathrm{m}$ & $26.8 \mu \mathrm{m}$ & $28.5 \mu \mathrm{m}$ & $86.5 \mu \mathrm{m}$ \\
M6 & $21.6 \mu \mathrm{m}$ & $25.7 \mu \mathrm{m}$ & $40.1 \mu \mathrm{m}$ & $75.6 \mu \mathrm{m}$ \\
M7 & $23.1 \mu \mathrm{m}$ & $24 \mu \mathrm{m}$ & $31.5 \mu \mathrm{m}$ & $67.5 \mu \mathrm{m}$ \\
M8 & $26 \mu \mathrm{m}$ & $22.8 \mu \mathrm{m}$ & $32.4 \mu \mathrm{m}$ & $64.8 \mu \mathrm{m}$ \\
M9 & $24.4 \mu \mathrm{m}$ & $23.3 \mu \mathrm{m}$ & $30.1 \mu \mathrm{m}$ & $89.8 \mu \mathrm{m}$ \\
M10 & $21.1 \mu \mathrm{m}$ & $25.8 \mu \mathrm{m}$ & $40.2 \mu \mathrm{m}$ & $85.2 \mu \mathrm{m}$ \\
Median (IQR) & $23.25(3.97) \mu \mathrm{m}$ & $25.55(1.85) \mu \mathrm{m}$ & $32.3(8.62) \mu \mathrm{m}$ & $75.8(18.42) \mu \mathrm{m}$ \\
\hline
\end{tabular}

Regarding the trueness values, the Kruskal-Wallis test indicated that there is a statistically relevant difference between the groups $(p<0.001)$. The post-hoc analysis (Conover test) was also executed. The Medit i700 group displayed the best level of trueness with the mean value of $23.25 \mu \mathrm{m}$, closely followed by the PrimeScan group which displayed the mean of $25.55 \mu \mathrm{m}$. The Omnicam group showed a decrease in trueness with a mean of $32.3 \mu \mathrm{m}$ while the PlanScan group displayed the lowest level of trueness with a mean value of $75.8 \mu \mathrm{m}$. This translates into roughly $2.3 \mu \mathrm{m}$ difference in trueness between MedIT i700 and Cerec PrimeScan while Cerec Omnicam shows differences of $10 \mu \mathrm{m}$ and Planmeca Planscan presenting a difference in trueness up to $53 \mu \mathrm{m}$ (Figure 3).

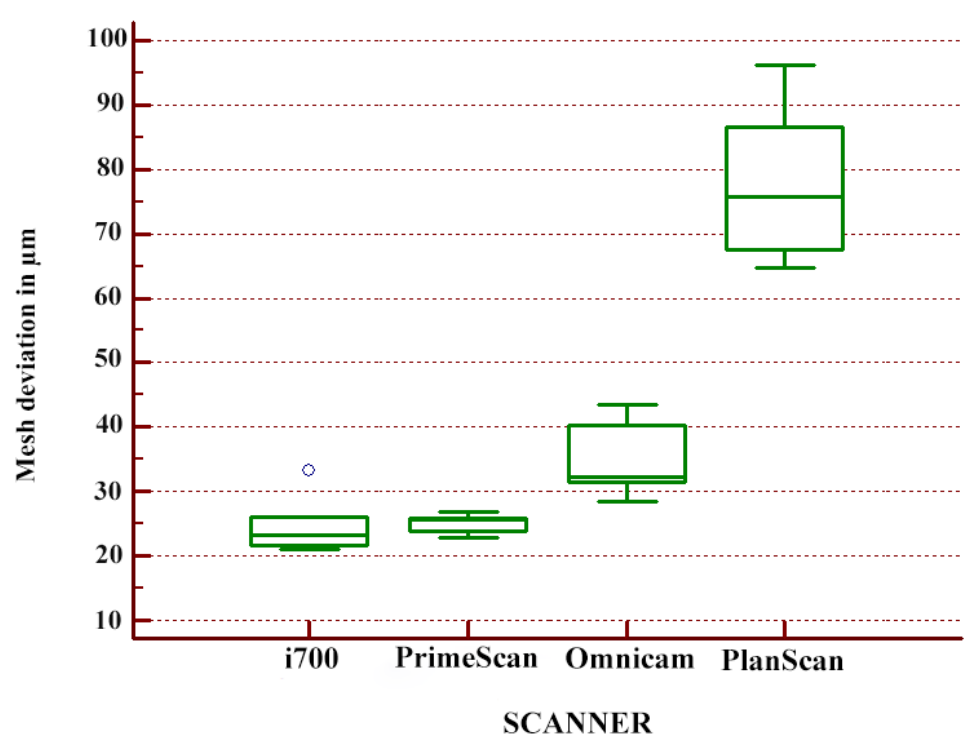

Figure 3. Boxplot displaying the trueness values of the four intraoral scanners. 
Table 3. Data obtained when comparing for precision.

\begin{tabular}{|c|c|c|c|c|}
\hline & Primescan & i700 & Omnicam & PlanScan \\
\hline M1 & $4.9 \mu \mathrm{m}$ & $7.6 \mu \mathrm{m}$ & $15.4 \mu \mathrm{m}$ & $28.2 \mu \mathrm{m}$ \\
\hline M2 & $6.6 \mu \mathrm{m}$ & $11.3 \mu \mathrm{m}$ & $17.1 \mu \mathrm{m}$ & $26.7 \mu \mathrm{m}$ \\
\hline M3 & $6.5 \mu \mathrm{m}$ & $13.8 \mu \mathrm{m}$ & $37.9 \mu \mathrm{m}$ & $73.5 \mu \mathrm{m}$ \\
\hline M4 & $6.5 \mu \mathrm{m}$ & $7.6 \mu \mathrm{m}$ & $15.9 \mu \mathrm{m}$ & $60.8 \mu \mathrm{m}$ \\
\hline M5 & $6.8 \mu \mathrm{m}$ & $11.4 \mu \mathrm{m}$ & $17.4 \mu \mathrm{m}$ & $74.2 \mu \mathrm{m}$ \\
\hline M6 & $5.8 \mu \mathrm{m}$ & $7.7 \mu \mathrm{m}$ & $15.8 \mu \mathrm{m}$ & $64.2 \mu \mathrm{m}$ \\
\hline M7 & $4.7 \mu \mathrm{m}$ & $7.6 \mu \mathrm{m}$ & $33.4 \mu \mathrm{m}$ & $78.9 \mu \mathrm{m}$ \\
\hline M8 & $6.4 \mu \mathrm{m}$ & $13.1 \mu \mathrm{m}$ & $15.3 \mu \mathrm{m}$ & $61.4 \mu \mathrm{m}$ \\
\hline M9 & $7.3 \mu \mathrm{m}$ & $14 \mu \mathrm{m}$ & $13.1 \mu \mathrm{m}$ & $29.3 \mu \mathrm{m}$ \\
\hline M10 & $7.1 \mu \mathrm{m}$ & $14.7 \mu \mathrm{m}$ & $12.4 \mu \mathrm{m}$ & $27.8 \mu \mathrm{m}$ \\
\hline M11 & $6 \mu \mathrm{m}$ & $9.1 \mu \mathrm{m}$ & $17.8 \mu \mathrm{m}$ & $90.1 \mu \mathrm{m}$ \\
\hline M12 & $7.1 \mu \mathrm{m}$ & $8 \mu \mathrm{m}$ & $13.4 \mu \mathrm{m}$ & $97 \mu \mathrm{m}$ \\
\hline M13 & $6.1 \mu \mathrm{m}$ & $7.9 \mu \mathrm{m}$ & $13.7 \mu \mathrm{m}$ & $60.8 \mu \mathrm{m}$ \\
\hline M14 & $7.2 \mu \mathrm{m}$ & $9.1 \mu \mathrm{m}$ & $15.1 \mu \mathrm{m}$ & $90.1 \mu \mathrm{m}$ \\
\hline M15 & $7.3 \mu \mathrm{m}$ & $11.2 \mu \mathrm{m}$ & $12.1 \mu \mathrm{m}$ & $64.2 \mu \mathrm{m}$ \\
\hline M16 & $6.8 \mu \mathrm{m}$ & $14.5 \mu \mathrm{m}$ & $13.4 \mu \mathrm{m}$ & $73.5 \mu \mathrm{m}$ \\
\hline M17 & $5.9 \mu \mathrm{m}$ & $9.4 \mu \mathrm{m}$ & $12.3 \mu \mathrm{m}$ & $91.1 \mu \mathrm{m}$ \\
\hline M18 & $6.8 \mu \mathrm{m}$ & $11.7 \mu \mathrm{m}$ & $33.7 \mu \mathrm{m}$ & $73.3 \mu \mathrm{m}$ \\
\hline M19 & $5.7 \mu \mathrm{m}$ & $9.1 \mu \mathrm{m}$ & $12.9 \mu \mathrm{m}$ & $72.5 \mu \mathrm{m}$ \\
\hline M20 & $5.8 \mu \mathrm{m}$ & $7.3 \mu \mathrm{m}$ & $13.4 \mu \mathrm{m}$ & $22.2 \mu \mathrm{m}$ \\
\hline M21 & $7.8 \mu \mathrm{m}$ & $5.4 \mu \mathrm{m}$ & $17.4 \mu \mathrm{m}$ & $74.4 \mu \mathrm{m}$ \\
\hline M22 & $6.4 \mu \mathrm{m}$ & $7.8 \mu \mathrm{m}$ & $15.4 \mu \mathrm{m}$ & $61.7 \mu \mathrm{m}$ \\
\hline M23 & $7.1 \mu \mathrm{m}$ & $14.7 \mu \mathrm{m}$ & $17.1 \mu \mathrm{m}$ & $29.1 \mu \mathrm{m}$ \\
\hline M24 & $6.5 \mu \mathrm{m}$ & $8.1 \mu \mathrm{m}$ & $17.3 \mu \mathrm{m}$ & $74.3 \mu \mathrm{m}$ \\
\hline M25 & $7.3 \mu \mathrm{m}$ & $5.4 \mu \mathrm{m}$ & $14.5 \mu \mathrm{m}$ & $22.2 \mu \mathrm{m}$ \\
\hline M26 & $4.9 \mu \mathrm{m}$ & $13.1 \mu \mathrm{m}$ & $15.2 \mu \mathrm{m}$ & $73.5 \mu \mathrm{m}$ \\
\hline M27 & $5.3 \mu \mathrm{m}$ & $14.4 \mu \mathrm{m}$ & $32.1 \mu \mathrm{m}$ & $90.1 \mu \mathrm{m}$ \\
\hline M28 & $7.3 \mu \mathrm{m}$ & $11.2 \mu \mathrm{m}$ & $32.9 \mu \mathrm{m}$ & $73.5 \mu \mathrm{m}$ \\
\hline M29 & $6 \mu \mathrm{m}$ & $5.4 \mu \mathrm{m}$ & $13.3 \mu \mathrm{m}$ & $77.1 \mu \mathrm{m}$ \\
\hline M30 & $7.2 \mu \mathrm{m}$ & $5.9 \mu \mathrm{m}$ & $15.9 \mu \mathrm{m}$ & $22.9 \mu \mathrm{m}$ \\
\hline M31 & $6.6 \mu \mathrm{m}$ & $7.4 \mu \mathrm{m}$ & $13.1 \mu \mathrm{m}$ & $60.4 \mu \mathrm{m}$ \\
\hline M32 & $4.7 \mu \mathrm{m}$ & $7.8 \mu \mathrm{m}$ & $17.2 \mu \mathrm{m}$ & $97.8 \mu \mathrm{m}$ \\
\hline M33 & $4.8 \mu \mathrm{m}$ & $11.3 \mu \mathrm{m}$ & $33.2 \mu \mathrm{m}$ & $61.5 \mu \mathrm{m}$ \\
\hline M34 & $5.8 \mu \mathrm{m}$ & $11.1 \mu \mathrm{m}$ & $13.4 \mu \mathrm{m}$ & $62.6 \mu \mathrm{m}$ \\
\hline M35 & $7.3 \mu \mathrm{m}$ & $7.5 \mu \mathrm{m}$ & $12.3 \mu \mathrm{m}$ & $75.2 \mu \mathrm{m}$ \\
\hline M36 & $5.9 \mu \mathrm{m}$ & $7.9 \mu \mathrm{m}$ & $15.6 \mu \mathrm{m}$ & $29.3 \mu \mathrm{m}$ \\
\hline M37 & $6.5 \mu \mathrm{m}$ & $9.2 \mu \mathrm{m}$ & $17.9 \mu \mathrm{m}$ & $91.4 \mu \mathrm{m}$ \\
\hline M38 & $6.6 \mu \mathrm{m}$ & $8 \mu \mathrm{m}$ & $18.3 \mu \mathrm{m}$ & $64.7 \mu \mathrm{m}$ \\
\hline M39 & $7.1 \mu \mathrm{m}$ & $9.1 \mu \mathrm{m}$ & $15.9 \mu \mathrm{m}$ & $78.9 \mu \mathrm{m}$ \\
\hline M40 & $4.8 \mu \mathrm{m}$ & $7.3 \mu \mathrm{m}$ & $12.3 \mu \mathrm{m}$ & $22.5 \mu \mathrm{m}$ \\
\hline M41 & $4.9 \mu \mathrm{m}$ & $13.2 \mu \mathrm{m}$ & $13.4 \mu \mathrm{m}$ & $24.3 \mu \mathrm{m}$ \\
\hline M42 & $5.7 \mu \mathrm{m}$ & $11.2 \mu \mathrm{m}$ & $14.5 \mu \mathrm{m}$ & $60.1 \mu \mathrm{m}$ \\
\hline M43 & $6.5 \mu \mathrm{m}$ & $14.6 \mu \mathrm{m}$ & $13.6 \mu \mathrm{m}$ & $68 \mu \mathrm{m}$ \\
\hline M44 & $7.1 \mu \mathrm{m}$ & $9.3 \mu \mathrm{m}$ & $33.4 \mu \mathrm{m}$ & $90.3 \mu \mathrm{m}$ \\
\hline M45 & $6.4 \mu \mathrm{m}$ & $7.4 \mu \mathrm{m}$ & $13.4 \mu \mathrm{m}$ & $74.3 \mu \mathrm{m}$ \\
\hline Median (IQR) & $6.5(1.3) \mu \mathrm{m}$ & $9.1(3.8) \mu \mathrm{m}$ & $15.4(4) \mu \mathrm{m}$ & $68(15.1) \mu \mathrm{m}$ \\
\hline
\end{tabular}

Regarding the precision values, the Kruskal-Wallis test returned a value of $p<0.001$, rejecting the null hypothesis and showing that the groups differ significantly. The post hoc analysis (Conover test) concluded that the PrimeScan group shows the best precision, the Medit i700 group being second in precision performance, the Omnicam group shows a decrease in precision and the PlanScan group being the least precise (Figure 4). 


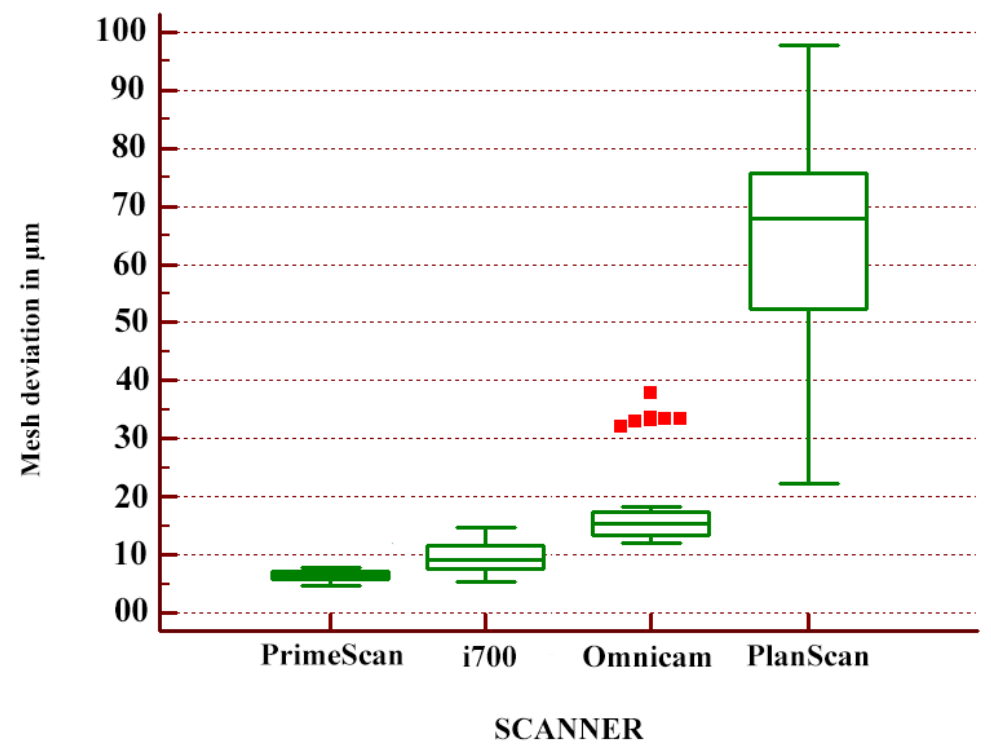

Figure 4. Boxplot displaying the precision values of the four intraoral scanners.

\section{Discussion}

Accuracy of digital impressions is essential in order to obtain high-quality restorations as well as to the predictability of the treatment [20]. The aim of IOSs is to increase the patient's acceptance and comfort, reduce the clinical time and also to eliminate the errors that come with the conventional impression procedure [21].

Today, with more and more IOSs being present in the dental offices, there are clinicians who are unsure whether or not there is a real need to replace the existing IOS with a newer one. Thus, the following question arises: "Is the accuracy of the older generation of IOSs an impediment for obtaining a quality intraoral digital impression?"

The results of the present in vitro study were in favor of the null hypothesis that the accuracy of the latest IOSs has improved significantly when compared to older generations of scanners.

The trueness and precision of intraoral scanners has been investigated in numerous scenarios by different authors. The results of this study were consistent with the results of other previous studies [22-24]. Mutwalli et al. evaluated the accuracy of three IOS (Trios 3, Trios 3 mono, Itero element) and obtained significant differences between the digital impressions [22]. Diker and Tak evaluated the accuracy of six IOS in the scenario of multiple single crown preparations distributed across a dentate arch. They reported the highest accuracy (trueness, precision) for Primescan $(25$ and $10 \mu \mathrm{m})$, followed by Trios (40.5 and $11 \mu \mathrm{m})$, Omnicam (41.5 and $18 \mu \mathrm{m})$, Virtuo Vivo (52 and $37 \mu \mathrm{m})$, iTero (70 and $12 \mu \mathrm{m})$ and Emerald $(73.5$ and $60 \mu \mathrm{m})$ [23]. Ender et al. also evaluated the trueness and precision of eight IOS and concluded that there were significant differences between the digital impressions, the best values being obtained for the Primescan IOS [24].

The clinical accuracy of impressions dictates the marginal and internal fit of the final restorations. However, all the following steps involved in the fabrication of the restoration may also introduce errors $[25,26]$. Even though CEREC Omnicam and Planmeca PlanScan are available on the market for almost nine years, the Omnicam IOS provides high-quality intraoral scans which are not far behind (difference of approx. $10 \mu \mathrm{m}$ ) of those obtained with the latest IOSs. On the other hand, the differences in trueness between the Planmeca PlanScan IOS when compared to Primescan and Medit i700 were significantly higher (difference of approx. $53 \mu \mathrm{m}$ ).

Regarding the precision of the investigated IOSs, the mean best performance was found for the Primescan IOS, followed by Medit i700, Omnicam and Planmeca IOSs. Primescan and Medit 1700 displayed precision values that are very close within the same interval of $5 \mu \mathrm{m}$ to $15 \mu \mathrm{m}$, with Primescan definitely keeping the median lower than $7 \mu \mathrm{m}$. 
Omnicam and Planmeca Planscan displayed values that differ significantly, with more outliers and resulting in a severe decrease of precision.

The accuracy of digital impression is conditioned by a number of external factors including the type of preparation, fluid isolation, limited space and access for the scanner, scanning area as well as lighting conditions in the office [27-30]. Being an in vitro study, there were a number of limitations. No clinical external factors were simulated (humidity, blood, patient movements). The scanning pattern was the same for all the IOSs, even though previous studies show conflicting reports regarding the influence of the scanning path on the final accuracy of digital impressions [31,32]. As another limitation, a better material could have been used to fill the gap of the edentulous area. Scannable impression materials such as Honigum Pro Scan (DMG) would have been more suitable for the scanning procedure and could have reduced the influence of the reflection of the material. Although the material not being ideal, it must be taken into account that the influence of the reflection of the material was constant throughout the entire experiment as the scans were performed in the same context and under the exact same conditions.

\section{Conclusions}

Based on the results of the present study, the following conclusion can be drawn:

1. Both CEREC PrimeScan and Medit i700 IOSs generated digital impressions with the highest accuracy of all the investigated IOSs;

2. Even if there is a time gap of +7 years between Omnicam and the first two mentioned IOSs, the difference in trueness and precision was low (approx. $10 \mu \mathrm{m}$ ). The Planscan IOS showed the lowest accuracy, even when compared with Omnicam IOS.

Author Contributions: A.J.: Substantial contributions to the conception or design of the work, interpretation of data, final approval of the version to be published; A.B.: Data collection; A.-B.F.: acquisition, analysis and interpretation of data for the work, critical revision of the article; R.N.R.: acquisition, analysis, and interpretation of data for the work, critical revision of the article; All authors have read and agreed to the published version of the manuscript.

Funding: This research received no external funding.

Institutional Review Board Statement: Not applicable.

Informed Consent Statement: Not applicable.

Data Availability Statement: All data are available upon request.

Conflicts of Interest: The authors declare no conflict of interest.

\section{Abbreviations}

The following abbreviations are used in this manuscript:

IOS Intraoral Scanner

\section{References}

1. Kihara, H.; Hatakeyama, W.; Komine, F.; Takafuji, K.; Takahashi, T.; Yokota, J.; Oriso, K.; Kondo, H. Accuracy and practicality of intraoral scanner in dentistry: A literature review. J. Prosthodont. Res. 2020, 64, 109-113. [CrossRef] [PubMed]

2. Jang, D.; Son, K.; Lee, K.B. A Comparative Study of the Fitness and Trueness of a Three-Unit Fixed Dental Prosthesis Fabricated Using Two Digital Workflows. Appl. Sci. 2019, 9, 2778. [CrossRef] [CrossRef]

3. Park, G.H.; Son, K.; Lee, K.B. Feasibility of using an intraoral scanner for a complete-arch digital scan. J. Prosthet. Dent. 2019, 121, 803-810. [CrossRef]

4. M.; elli, F.; Ferrini, F.; Gastaldi, G.; Gherlone, E.; Ferrari, M. Improvement of a Digital Impression with Conventional Materials: Overcoming Intraoral Scanner Limitations. Int. J. Prosthodont. 2017, 30, 373-376. [CrossRef] [PubMed]

5. Papaspyridakos, P.; Kang, K.; DeFuria, C.; Amin, S.; Kudara, Y.; Weber, H.P. Digital workflow in full-arch implant rehabilitation with segmented minimally veneered monolithic zirconia fixed dental prostheses: 2-year clinical follow-up. J. Esthet. Restor. Dent. 2018, 30, 5-13. [CrossRef] 
6. Rossini, G.; Parrini, S.; Castroflorio, T.; Deregibus, A.; Debernardi, C.L. Diagnostic accuracy and measurement sensitivity of digital models for orthodontic purposes: A systematic review. Am. J. Orthod. Dentofac. Orthop. 2016, 149, 161-170. [CrossRef]

7. Flügge, T.; van der Meer, W.J.; Gonzalez, B.G.; Vach, K.; Wismeijer, D.; Wang, P. The accuracy of different dental impression techniques for implant-supported dental prostheses: A systematic review and meta-analysis. Clin. Oral Implant. Res. 2018, 29 (Suppl. S16) 374-392. [CrossRef]

8. Nedelcu, R.; Olsson, P.; Nyström, I.; Rydén, J.; Thor, A. Accuracy and precision of 3 intraoral scanners and accuracy of conventional impressions: A novel in vivo analysis method. J. Dent. 2018, 69, 110-118. [CrossRef] [PubMed]

9. Solaberrieta, E.; Garmendia, A.; Brizuela, A.; Otegi, J.R.; Pradies, G.; Szentpétery, A. Intraoral Digital Impressions for Virtual Occlusal Records: Section Quantity and Dimensions. Biomed. Res. Int. 2016, 2016, 7173824. [CrossRef]

10. Mangano, F.; Gandolfi, A.; Luongo, G.; Logozzo, S. Intraoral scanners in dentistry: A review of the current literature. BMC Oral Health 2017, 17, 149. [CrossRef]

11. Miyazaki, T.; Hotta, Y.; Kunii, J.; Kuriyama, S.; Tamaki, Y. A review of dental CAD/CAM: Current status and future perspectives from 20 years of experience. Dent. Mater. J. 2009, 28, 44-56. [CrossRef]

12. Atieh, M.A.; Ritter, A.V.; Ko, C.C.; Duqum, I. Accuracy evaluation of intraoral optical impressions: A clinical study using a reference appliance. J. Prosthet. Dent. 2017, 118, 400-405. [CrossRef]

13. Gan, N.; Xiong, Y.; Jiao, T. Accuracy of Intraoral Digital Impressions for Whole Upper Jaws, Including Full Dentitions and Palatal Soft Tissues. PLoS ONE 2016, 11, e0158800. [CrossRef] [PubMed]

14. Ender, A.; Attin, T.; Mehl, A. In vivo precision of conventional and digital methods of obtaining complete-arch dental impressions. J. Prosthet. Dent. 2016, 115, 313-320. [CrossRef] [PubMed]

15. Chochlidakis, K.M.; Papaspyridakos, P.; Geminiani, A.; Chen, C.J.; Feng, I.J.; Ercoli, C. Digital versus conventional impressions for fixed prosthodontics: A systematic review and meta-analysis. J. Prosthet. Dent. 2016, 116, 184-190.e12. [CrossRef] [PubMed]

16. Revell, G.; Simon, B.; Mennito, A.; Evans, Z.P.; Renne, W.; Ludlow, M.; Vág, J. Evaluation of complete-arch implant scanning with 5 different intraoral scanners in terms of trueness and operator experience. J. Prosthet. Dent. 2021. [CrossRef] [PubMed]

17. Burzynski, J.A.; Firestone, A.R.; Beck, F.M.; Fields, H.W., Jr.; Deguchi, T. Comparison of digital intraoral scanners and alginate impressions: Time and patient satisfaction. Am. J. Orthod. Dentofac. Orthop. 2018, 153, 534-541. [CrossRef] [PubMed]

18. Available online: https:/ / www.medit.com/dental-clinic-i700 (accessed on 15 June 2021).

19. Available online: https://universadent.com/product/medit-t500/ (accessed on 15 June 2021).

20. Yang, X.; Lv, P.; Liu, Y.; Si, W.; Feng, H. Accuracy of Digital Impressions and Fitness of Single Crowns Based on Digital Impressions. Materials 2015, 8, 3945-3957. [CrossRef] [PubMed]

21. Persson, A.S.; Odén, A.; Andersson, M.; Sandborgh-Englund, G. Digitization of simulated clinical dental impressions: virtual three- dimensional analysis of exactness. Dent. Mater. 2009, 25, 929-936. [CrossRef] [PubMed]

22. Mutwalli, H.; Braian, M.; Mahmood, D.; Larsson, C. Trueness and Precision of Three-Dimensional Digitizing Intraoral Devices. Int. J. Dent. 2018, 2018, 5189761. [CrossRef]

23. Diker, B.; Tak, Ö. Comparing the accuracy of six intraoral scanners on prepared teeth and effect of scanning sequence. J. Adv. Prosthodont. 2020, 12, 299-306. [CrossRef]

24. Ender, A.; Zimmermann, M.; Mehl, A. Accuracy of complete- and partial-arch impressions of actual intraoral scanning systems in vitro. Int. J. Comput. Dent. 2019, 22, 11-19. [PubMed]

25. Goujat, A.; Abouelleil, H.; Colon, P.; Jeannin, C.; Pradelle, N.; Seux, D.; Grosgogeat, B. Marginal and internal fit of CAD-CAM inlay/onlay restorations: A systematic review of in vitro studies. J. Prosthet. Dent. 2019, 121, 590-597.e3. [CrossRef]

26. Homsy, F.R.; Özcan, M.; Khoury, M.; Majzoub, Z.A.K. Marginal and internal fit of pressed lithium disilicate inlays fabricated with milling, 3D printing, and conventional technologies. J. Prosthet. Dent. 2018, 119, 783-790. [CrossRef]

27. Arakida, T.; Kanazawa, M.; Iwaki, M.; Suzuki, T.; Minakuchi, S. Evaluating the influence of ambient light on scanning trueness, precision, and time of intra oral scanner. J. Prosthodont. Res. 2018, 62, 324-329. [CrossRef] [PubMed]

28. Park, H.N.; Lim, Y.J.; Yi, W.J.; Han, J.S.; Lee, S.P. A comparison of the accuracy of intraoral scanners using an intraoral environment simulator. J. Adv. Prosthodont. 2018, 10, 58-64. [CrossRef] [PubMed]

29. Kurz, M.; Attin, T.; Mehl, A. Influence of material surface on the scanning error of a powder-free 3D measuring system. Clin. Oral Investig. 2015, 19, 2035-2043. [CrossRef] [PubMed]

30. Dupagne, L.; Tapie, L.; Lebon, N.; Mawussi, B. Comparison of the acquisition accuracy and digitizing noise of 9 intraoral and extraoral scanners: An objective method. J. Prosthet. Dent. 2021. [CrossRef] [PubMed]

31. Latham, J.; Ludlow, M.; Mennito, A.; Kelly, A.; Evans, Z.; Renne, W. Effect of scan pattern on complete-arch scans with 4 digital scanners. J. Prosthet. Dent. 2020, 123, 85-95. [CrossRef] [PubMed]

32. Son, K.; Jin, M.U.; Lee, K.B. Feasibility of using an intraoral scanner for a complete-arch digital scan, part 2: A comparison of scan strategies. J. Prosthet. Dent. 2021. [CrossRef] 